\title{
Development of Moscow region passenger transport system using discrete mathematics methods
}

\author{
Denis Vlasov ${ }^{1 *}$, and Vladislav Rasov ${ }^{1}$ \\ ${ }^{1}$ Moscow State University of Civil Engineering (NRU MGSU), 26, Yaroslavskoye Shosse, Moscow, \\ 129337, Russia
}

\begin{abstract}
Transformation of settlement systems, consolidation of existing cities to the level of agglomerations, conurbations and megalopolises require a qualitative change in the transport system. Today Moscow and the Moscow region are in the stage of active development and interaction. The most important issue is to ensure transport connectivity and territory accessibility. The high cost of infrastructure projects and their duration require high-quality justification of decisions to be made. This publication discusses the use of the theory of graphs in the development of Light-RailTransit (LRT) systems, which are planned to be used as an element of the new unified transport system of Moscow agglomeration. The materials for the article are data on the existing and planned development of Moscow region settlements, the basis for calculations is the mathematical apparatus of the theory of graphs. The result of the work is represented by recommendations on the use of the theory of graphs for the purposes of substantiation of Moscow region transport system development, as well as main areas for continuing research were determined.
\end{abstract}

\section{Introduction}

The effective functioning of the passenger transport system of an agglomeration is a basis for the sustainable urban development. Sustainable development involves provision of safe and favourable conditions for human life, mitigation of the negative impact on the environment, preservation and rational use of natural resources, preservation of the historical and cultural heritage, local traditions and characteristics for the current and next generations.

Currently there is a deviation from sustainable development on the territory of Moscow agglomeration. A combination of external and internal factors resulted in the following distortions:

- High-density residential development in the central part of the Moscow region and no concurrent development of transport infrastructure.

- Overloading and deterioration in the reliability of transport infrastructure as a whole and the passenger transport network in particular (the load on the main sections of

\footnotetext{
*Corresponding author: vlasych@mail.ru
} 
highways during peak hours is close to critical).

- A significant increase in labor push-pull migration (over the past 10 years it increased by $30 \%[1])$.

- Environmental degradation in the region.

The solution could be the creation of a conurbation in the Moscow region - several equivalent centres attracting human resources [2].

The object of research in this article is the passenger transport system of Moscow agglomeration, so the most interesting problem to study is the growth of labor push-pull migration. An important component of creating a sustainable public transport network of the agglomeration is the development of a system of passenger hubs [11], [12], [13], [14]. When elaborating a passenger hubs development plan, the top-priority problem is to satisfy needs for access for passengers and vehicles with their unique characteristics. The principles of transit-oriented development are aimed at solving such problems [3].

\section{Materials and methods}

The creation of a coherent intermodal system of passenger transport in Moscow agglomeration is a complex problem that requires an integrated approach and taking into account many factors of spatial (urban) development.

General layouts of municipal structures, draft plans of area- and linear-type facilities approved by competent authorities are proposed to be used as materials for calculating and analyzing town-planning characteristics of the territory. The most important characteristics are population, labor resources, planned new housing and the creation of a significant number of workplaces in the territory under consideration. To build a network graph, it is proposed to use graphic materials of general layouts; in particular, plans of transport infrastructure development within the boundaries of municipal structures.

The territory that is most suitable for research from the point of view of the problems set was determined in the course of analysis of Moscow region land-use planning documents. The territory under consideration includes Podolsk, Domodedovo, Zhukovsky, Lytkarino, Dzerzhinsky, Lyubertsy, Kotelniki, Balashikha urban districts, as well as Leninsky and Ramensky municipal districts. The considered territory also includes Gorkov, Ryazan, Paveletsk, Kursk directions of the Moscow railway, Domodedovo and Zhukovsky airports are also located there. The existing and planned population, as well as the number of workplaces were calculated in the process of determining the aggregated town-planning characteristics of municipal structures. In accordance with the territorial planning documents, new residential and industrial capacities will be commissioned in stages. It is proposed to determine three time periods for the development of the territory under consideration: the current situation, the medium term and the target date (presumably 2035). It will be necessary to determine the geometric center, as well as the territorial location of the focus of gravity associated either with the new housing supply or the creation of a large number of workplaces in each transport region at the corresponding stage of development.

In the course of results analysis municipal structures with the least balanced urban development were determined. So, for example, in Vidnoe, Lytkarino, Dzerzhinsky, and Lyubertsy urban districts commissioning of a significant amount of new high-density housing is planned, which will result in an increase in the population by $1.5-2$ times. In turn, it is planned to implement industrial clusters and special economic zones and create new jobs in the territory of Domodedovo, Ramensky, and Podolsk urban districts. Sustainable development in these territories is not possible without the concurrent development of transport infrastructure. In this regard the Territorial Planning Scheme of the Moscow Region for the Development of Transport Infrastructure (TPS MR DT) 
provides for the development of the urban motorway network and the creation of a unified network of high-speed passenger transport (including high-speed trams).

We propose the following methodology (Fig. 1) for studying the prerequisites for the formation of an interconnected intermodal system of passenger transport [4-6] in the Moscow region using elements of the theory of graphs:

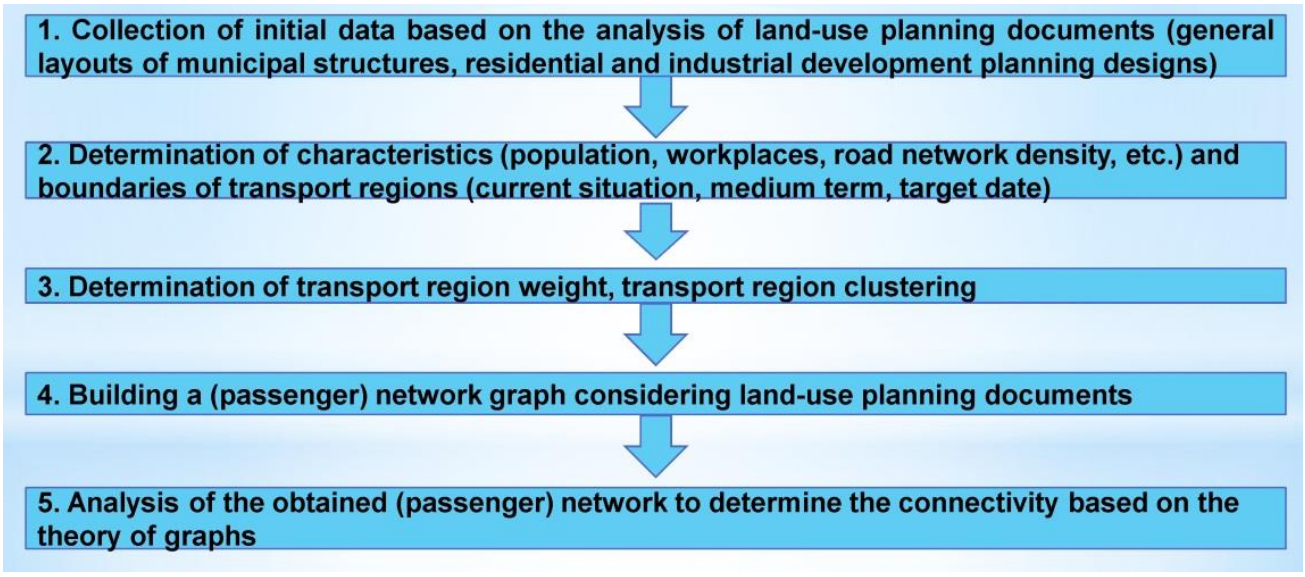

Fig. 1. Proposed research methodology

The main objective of the study is to find the optimum structure of a high-speed LRT system, which will be based on high-speed tram lines, so it is necessary to determine the main connectivity characteristics of such a system.

One of the methods of discrete mathematics will be used as a theoretical basis of our study - it is the theory of graphs. The basic concept of the theory of graphs is graph connectivity [7].

A connected graph contains the only one connectivity component, which means that there is at least one path between any pair of vertices of this graph (1):

where $\mathbf{v}$ is the number of graph vertices,

$$
v-e+f=2
$$

$\mathbf{e}$ is the number of graph edges,

$\mathrm{f}$ is the number of graph faces.

\section{Theory and calculations}

Network connectivity determines the number of connections within the transport network and their nature. High connectivity is characterized by low isolation and high availability of network graph vertices. Network connectivity is also a measure of the accessibility of transport areas without taking into account the distance between them.

To determine graph connectivity, it is necessary to build a transport network of the territory under consideration.

The transport network in the theory of graphs is a directed graph $G(v, e)$, in which $\mathbf{v}$ is a set of graph vertices and $\mathbf{e}$ is a set of graph edges.

In the adopted research methodology, a vertice of the graph means a transport region with its inherent characteristics (population, number of workplaces, etc.), and a graph edge is a section of the network of high-speed LRT with a bandwidth corresponding to the type of the passenger transport [8].

The studied graph should be planar (be in one plane), oriented, and also should have a connectivity component. 
This study uses the following connectivity characteristics of a transport network [9,10].

Graph diameter (d) is the length of the shortest path between the most distant nodes of the graph. It measures the length of the graph and the topological length between two nodes.

The number of cycles in the graph (u) is the number of sequences of graph vertices starting and ending at the same vertice, despite the fact that for any two consecutive vertices there is an edge from the earlier one to the later one.

Alpha index $(\boldsymbol{\alpha})$ is a measure of connectivity that estimates the number of cycles in the network graph compared to the maximum number of cycles, provided that all vertices are directly connected (2):

$$
\alpha=\frac{u}{2 v-5}
$$

Beta index $(\boldsymbol{\beta})$ is used to measure the level of connectivity in the graph and is expressed by the ratio of the number of edges (e) to the number of vertices (v). The more complex the network graph is, the higher the beta index is (3):

$$
\beta=\frac{\mathrm{e}}{\mathrm{v}}
$$

Gamma index $(\gamma)$ is a measure of connectivity that takes into account the relationship between the number of actual and possible connections. The gamma value is between 0 and 1. Value 1 means that any two nodes of the graph are interconnected, which, from the point of view of the network of high-speed LRT, is an unlikely event. The gamma index is effective for measuring changes in the transport network over time (4):

$$
\gamma=\frac{\mathrm{e}}{3(\mathrm{v}-2)}
$$

\section{Results}

So, based on the consolidated town-planning characteristics and measures provided for in the TPS MR DT as regards to high-speed tram lines, transport network options have been developed that reflect the existing and perspective (Figure 3) position of high-speed LRT development [11]. Based on the transport networks, the corresponding network graphs were constructed (Figure 4) for their further analysis.
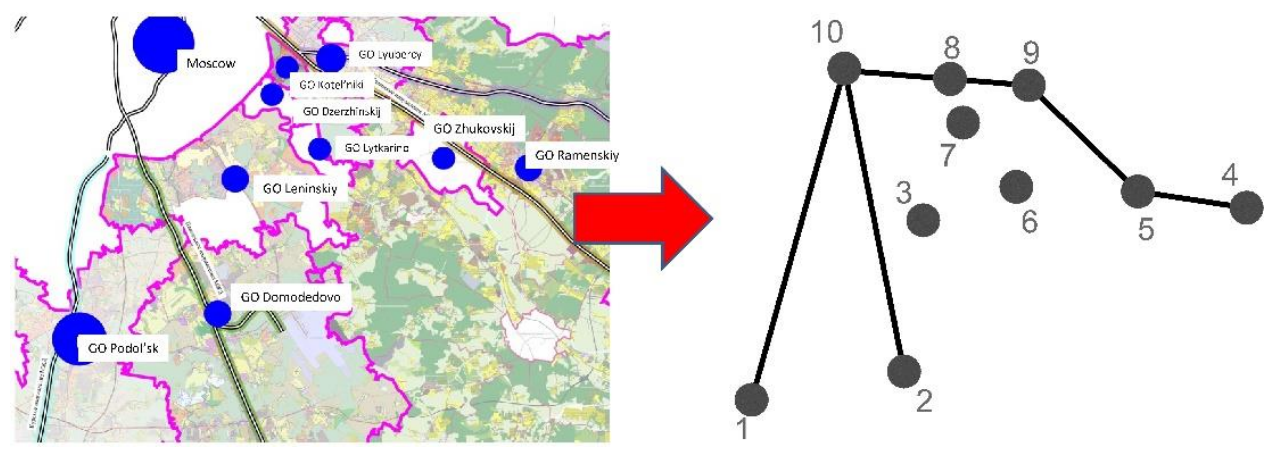

Fig. 3. Existing and graph network of high-speed LRT

As a result of the analysis of the graph of the existing network of high-speed LRT, it turned out that it does not have connectivity components, which indicates that not all municipal structures in the south-east of Moscow agglomeration have direct access to the high-speed passenger transport network. Such a network is not connected and cannot be considered as an object for further research.

The graph of a perspective network of high-speed LRT of the territory under consideration satisfies all the conditions, i.e. it is oriented, planar and contains a 
connectivity component. The characteristics mentioned above were calculated for it (Table 1):

Table 1. Characteristics of the perspective graph of a transport network.

\begin{tabular}{|l|l|l|}
\hline No. & Characteristics & Value \\
\hline 1 & Number of nodes & 10 \\
\hline 2 & Number of edges & 12 \\
\hline 3 & Diametrality & 4 \\
\hline 4 & Number of cycles & 3 \\
\hline 5 & Alpha index & 0.2 \\
\hline 6 & Beta index & 1.2 \\
\hline 7 & Gamma index & 0.5 \\
\hline
\end{tabular}

\section{Discussion}

The creation of an intermodal passenger transport system will lead to a redistribution of traffic flows and an increase in the quality of passenger transport services.

When creating such a system, it is necessary to use elements of discrete mathematics the theory of graphs. Elements of the theory of graphs can be used to determine alpha, beta and gamma indices of the network of high-speed passenger transport, which characterize the degree of transport system connectivity [12].

The basis of such a transport system may be high-speed rail passenger transport, including such currently relevant type of light transport as high-speed trams [13].

The objectives of the development of high-speed rail passenger transport are as follows:

- A decrease in the traffic load on the road network by attracting passengers to light rail transit.

- Creation of an alternative means of public transport.

- Provision of passenger transport links in the chord direction between residential, public and industrial territories.

- An increase in the quality of transport services by reducing the time of transportation between the centers of passenger flows attraction.

- Provision of fast, convenient and reliable transport communication.

- Creation of a unified system of high-speed passenger transport in Moscow and the Moscow region.

Further research on this issue may have two lines. One line is to test the methodology using the system of high-speed passenger transport of Moscow agglomeration as a whole. The other one is to refine town-planning characteristics of the south-western territory of the agglomeration considered in the article and determine their impact on the formation of such a system.

\section{Conclusions}

So, the creation of an intermodal passenger transport system of Moscow agglomeration is an important and urgent task in view of the existing urban development problems associated with the oversaturation of passenger highways and mass commissioning of highdensity housing without the concurrent development of the necessary infrastructures. The solution to this problem may be to use the elements of the theory of graphs related to the construction of transport networks in order to determine the connectivity parameters of the graph of the resulting network of high-speed passenger transport. It is also required to conduct an additional study of urban development characteristics of the proposed transport 
regions to ensure a sustainable development $[14,15]$ of the territory under consideration and prioritize the formation of passenger transport links between the proposed transport regions. In addition, the authors of the study consider the provision of safe and favorable conditions for human life in the course of town-planning activities as the most important principle.

\section{References}

1. A. Makhrova, A. Bochkarev. Vestnik of Saint Petersburg University. Earth Sciences, 63(1), 56-68 (2018) DOI: 10.21638/11701/spbu07.2018.104

2. A. Voloshinskaya, V. Komarov. Actual Problems Of Economic Practice, 14(4), 92-108 (2017) DOI: 10.23683/2073-6606-2017-15-4-92-108

3. W.A. Xu, A. Guthrie et al. Journal of Transport and Land Use, 10(1), 1938-7849 (2017) DOI: 10.5198/jtlu.2017.922

4. P. Hall, K. Pain. The Polycentric Metropolis, 256 (2006) DOI: 10.4324/9781849773911

5. K. Boussauw, M. Van Meeteren et al. European Journal of Spatial Development, 69 (2018)

6. K. Kwon, M. Seo. Sustainability, 10(4157) (2018)

7. S. Guze. The International Journal on Marine Navigation and Safety of Sea Transportation, 4(8) (2014) DOI: 10.12716/1001.08.04.12

8. F. Rotoli, P. Christidis, L. Vannacci et al. Transportation Research Procedia, 3, 319328 (2014) DOI: 10.1016/j.trpro.2014.10.012

9. Y. Hadas, R. Rossi et al. Public Transportation Research Procedia, 3, 309-318 (2014)

10. G. Sethuraman, M. Sujasree. AKCE International Journal of Graphs and Combinatorics (2018) DOI: 10.1016/j.akcej.2018.11.003

11. A. Hong, G. Marlon et al. Houston Transportation Research Part A: Policy and Practice Elsevier, 92, 131-144 (2016) DOI: $\underline{10.1016 / \text { j.tra.2016.07.005 }}$

12. B. Boulmakoul, L. Karim et al. Transportation Research Procedia, 27, 1154-1162 (2018) DOI: 27. 10.1016/j.trpro.2017.12.019.

13. N.B. Hurst, S.E. West. Regional Science and Urban Economics, 46, 57-72 (2014) DOI: 10.1016/j.regsciurbeco.2014.02.002

14. R. Strulak-Wójcikiewicz, J. Lemke. Transportation Research Procedia, 39, 502-513 (2019) DOI: 502-513. 10.1016/j.trpro.2019.06.052

15. N. Vatin, N. Lavrov, G. Loginov. MATEC Web of Conferences. 2016. 73. DOI:10.1051/matecconf/20167301006. 